Please note that this is not the final peer-reviewed version of this manuscript. Please do not cite this version. The final peer-reviewed version is in press at Psychosomatic Medicine. This preprint will be updated with the doi for the peer-reviewed, published article when available.

See: Willroth, E. C., Smith, A. M., Shallcross, A.J., Graham, E. K., Mroczek, D., \& Ford, B. Q. (in press). The health behavior model of personality in the context of a public health crisis. Psychosomatic Medicine.

The Health Behavior Model of Personality in the Context of a Public Health Crisis

\author{
Emily C. Willroth, $\mathrm{PhD}^{1}$, Angela M. Smith, MA², Amanda J. Shallcross, MPH, ND², \\ Eileen K. Graham, $\mathrm{PhD}^{1}$, Daniel K. Mroczek, $\mathrm{PhD}^{1}$, Brett Q. Ford, $\mathrm{PhD}^{2}$
}

\author{
${ }^{1}$ Northwestern University \\ ${ }^{2}$ University of Toronto \\ ${ }^{3}$ New York University School of Medicine
}

Author Note: This research was funded by a Social Sciences and Humanities Research Council Insight Grant awarded to Brett Ford and a University of Toronto COVID-19 Student

Engagement Award awarded to Angela Smith. Correspondence regarding this manuscript should be addressed to Brett Ford (Brett.Ford@utoronto.ca); University of Toronto; 1265 Military Trail, SW427A; Toronto, Ontario, M1C 1A4, Canada. 


\begin{abstract}
Objectives: The U.S. Centers for Disease Control and Prevention (CDC) has recommended behavioral measures to slow the spread of COVID-19, such as social distancing and wearing masks. While many individuals comply with these recommendations, compliance has been far from universal. Identifying predictors of compliance is crucial for improving health-behavior messaging and thereby reducing disease spread and fatalities.
\end{abstract}

Method: Here, we report a pre-registered longitudinal study which investigated personality predictors of compliance with CDC recommendations in diverse U.S. adults across five waves from March through August, $2020(N=596)$ and cross-sectionally in August, $2020(N=405)$.

Results: Agreeableness — characterized by compassion — was a strong predictor of compliance, above and beyond other traits and demographic predictors. The effect of agreeableness was robust across two diverse samples, three sets of sensitivity analyses, and was not moderated by time or demographic variables.

Conclusions: Individuals who are less agreeable are at high-risk for non-compliance with behavioral mandates, suggesting that health messaging can be meaningfully improved with approaches that address these individuals in particular. Indeed, current health-behavior messaging may be especially misaligned with these individuals, as it has largely focused on appeals to agreeableness (e.g., compassion) by emphasizing the community-protective benefits of slowing the spread of COVID-19. Combining current health-behavior messaging with alternative appeals that are more likely to reach less agreeable individuals may be particularly effective. These findings highlight the strong theoretical and practical utility of testing longstanding psychological theories using rigorous methods during real-world crises.

Keywords: agreeableness, COVID-19, health behavior, personality, public health 


\section{The Health Behavior Model of Personality in the Context of a Public Health Crisis}

In the absence of an effective and broadly-disseminated vaccine or treatment, behavioral measures to control the spread of infectious diseases like COVID-19 are critically important (1). Although many people comply with these guidelines, behavioral strategies only work when there is wide-spread adoption, yet there is often pervasive non-compliance (2). Identifying the factors that contribute to individual differences in health behaviors is vital for improving efforts to increase compliance with public health guidance. Personality traits—characteristic patterns of thoughts, feelings, and behaviors - are powerful predictors of health behaviors (3-4). As such, a personality psychology perspective should be able to help us predict how people behave within large-scale, societal health crises. In turn, applying psychological theory to real-world crises can be practically useful: Namely, identifying personality predictors of COVID-19 health behaviors will reveal who is most likely to ignore behavioral mandates, which can then be used to improve public health messaging to better reach these individuals and in turn, increase compliance (5).

To inform the crucial time-sensitive question of what factors drive compliance with COVID-19 preventive health behaviors, we can leverage long-standing theories of personality. The health behavior model of personality posits that particular personality dimensions, derived from the Big Five theory of personality (6), influence health behaviors $(3,7)$. Although the majority of research on the health behavior model of personality has rarely considered acute infectious disease threats like COVID-19, the existing research and theory suggests that three traits may be particularly relevant: conscientiousness, agreeableness, and neuroticism. In particular, this work has found that conscientiousness - characterized by organization and responsibility — is generally the strongest predictor of health behaviors (3). This work has focused on individual health threats that hinge on self-protecting health behaviors (e.g., exercise 
habits to improve cardiovascular health). However, preventing the spread of the collective health threat of an infectious disease requires unique behaviors that are not only self-protecting, but also community-protecting (e.g., wearing a mask to protect others from infection). In this context, agreeableness — characterized by compassion and respect — may be particularly important:

Highly agreeable people's compassion for others may drive a desire to slow the disease's spread, and their tendency toward cooperation (8) may make them more likely to comply with behavioral recommendations. Finally, the vigilance required to reduce COVID-19 risk may also suggest that neuroticism—characterized by high levels of negative emotions such as worry—will predict greater compliance (9). This is consistent with the healthy neuroticism hypothesis, which suggests that neuroticism, especially in combination with conscientiousness, may lead to vigilance-based behaviors to avoid health threats (10-11).

The present study provides a methodologically-rigorous test of whether personality predicts compliance with COVID-19 preventive behaviors recommended by the U.S. Centers for Disease Control and Prevention (CDC) (12) during the first five months of the pandemic. Some prior research has begun to speak to this question using data from March and April (13-15). However, as the pandemic shows little signs of abating in the U.S., it is crucial to understand factors that drive long-term compliance. We addressed this critical question by assessing health behaviors each month in five waves of data collection between March through August, 2020. This longitudinal approach provides a robust test of personality-behavior links across time, as aspects of the situation change (e.g., as policies and social norms change), and allows us to test for moderation by time to determine the consistency of associations as the pandemic unfolds. To examine the generalizability of associations across diverse individuals, we collected two online samples of U.S. participants (Sample A $N=596$; Sample B $N=405$ ) that were diverse in terms of 
age, gender, racial identification, and political affiliation. Participants in Sample A were specifically recruited to be diverse with respect to racial identification. Participants in Sample B were specifically recruited to be diverse with respect to political affiliation.

Based on prior empirical and theoretical work, we preregistered the following predictions: higher agreeableness, conscientiousness, and neuroticism will predict greater engagement in COVID-19 preventive health behaviors, and the effect of neuroticism on health behaviors will be strongest at higher levels of conscientiousness. We did not make specific predictions for extraversion (characterized by assertiveness and sociability) or openness (characterized by intellect and creativity).

\section{Method}

All procedures were approved by the University of Toronto ethics board (protocol \#33962). The pre-registration, data, and statistical code are available at https://osf.io/ukvrh/.

\section{Participants and Procedure}

U.S. participants were recruited from Amazon’s Mechanical Turk. Participants provided informed consent and were compensated approximately $\$ 9$ per hour. Sample A $(N=596, \mathrm{M}=37$ years old, $S D=11$ ) was 55\% women, 34\% White, 30\% Black, 22\% Asian, 50\% Democrat, and $16 \%$ Republican. Sample B $(N=405, \mathrm{M}=44$ years old, $S D=13)$ was $51 \%$ women, $84 \%$ White, 53\% Republican, and 47\% Democrat. Sample A $(N=596)$ provided $90 \%$ statistical power to detect an effect of .13 or larger; Sample B $(N=405)$ provided $90 \%$ statistical power to detect an effect of .16 or larger. Power analyses were conducted in R using the pwr package (16).

We assessed personality in March in Sample A and in August in Sample B using the BFIII-XS (6). We used participants' ratings of how often they engaged in five CDC-recommended health behaviors (mask wearing, social distancing, self-isolation, sanitizing surfaces, and hand 
washing) "over the past four weeks" monthly from March through August in Sample A and in August in Sample B. Response options ranged from 0 (I did not do this) to 4 (I very often or always did this). Surveys with failed attention checks were excluded from analysis.

\section{Analytic Approach}

All analyses were conducted in R Version 3.6.1 using base R functions and the nlme package (17). In Sample A, we used random-intercept multilevel models to predict health behaviors from March through August from personality traits. In Sample B, we used multiple regression to predict health behaviors in August from personality traits. Age, education, gender, racial identification, and political affiliation were included as covariates in primary analyses. To examine the robustness of results, we conducted three sets of pre-registered sensitivity analyses: (1) simple associations without covariate adjustment; (2) unique associations controlling for other Big Five traits; and (3) associations with intended future health behaviors rather than past health behaviors.

\section{Results}

Agreeableness was the strongest predictor of health behaviors in Sample A (see Table 1). In the top quartile of agreeableness, $58 \%$ of participants engaged in health behaviors "often" or "very often or always," compared to only $36 \%$ of participants in the bottom quartile. Higher conscientiousness, extraversion, and open-mindedness were also positively associated with health behaviors, but effects were smaller and less consistent. Neuroticism was not associated with health behaviors and did not interact with conscientiousness to predict health behaviors. The direction and statistical significance of all primary results replicated in Sample B. 
Table 1

Primary Analyses: Personality Predictors of COVID-19 Preventive Health Behaviors

\begin{tabular}{|c|c|c|c|c|c|c|c|}
\hline $\begin{array}{l}\text { Sample A } \\
\text { (Longitudinal) }\end{array}$ & B & $95 \%$ CI & $p$ & $\begin{array}{l}\text { Sample B } \\
\text { (Cross-Sectional) }\end{array}$ & B & $95 \% \mathrm{CI}$ & $p$ \\
\hline Agreeableness & 0.25 & $0.18,0.32$ & $<.001$ & Agreeableness & 0.12 & $0.03,0.22$ & .011 \\
\hline Openness & 0.10 & $0.03,0.17$ & .005 & Openness & 0.16 & $0.06,0.25$ & .001 \\
\hline Conscientiousness & 0.15 & $0.08,0.22$ & $<.001$ & Conscientiousness & 0.13 & $0.04,0.22$ & .007 \\
\hline Extraversion & 0.14 & $0.07,0.21$ & $<.001$ & Extraversion & 0.11 & $0.02,0.21$ & .016 \\
\hline Neuroticism & -0.05 & $-0.12,0.02$ & .145 & Neuroticism & -0.04 & $-0.13,0.06$ & .477 \\
\hline $\begin{array}{l}\text { Neuroticism } \mathrm{x} \\
\text { Conscientiousness }\end{array}$ & -0.02 & $-0.08,0.05$ & .616 & $\begin{array}{l}\text { Neuroticism } \mathrm{x} \\
\text { Conscientiousness }\end{array}$ & 0.00 & $-0.10,0.09$ & .931 \\
\hline
\end{tabular}

Note. Each row shows results from a separate model. Age, education, gender, racial and ethnic identity, and political affiliation were included as covariates.

The link between agreeableness and health behaviors was not moderated by time, $\mathrm{B}=$ $.00, p=.99$, suggesting that agreeableness is consistently associated with greater compliance both in the early stages of the pandemic and afterwards, as the need for preventive behaviors becomes chronic. Moreover, the link between agreeableness and health behaviors was not moderated by age, gender, education, racial identification, or political affiliation, $|\mathrm{Bs}|<.10, p \mathrm{~s}>$ .055 , suggesting that the effect of agreeableness is generalizable across diverse individuals. In three sets of sensitivity analyses, agreeableness was the only consistent predictor across all analyses and in both samples (see Table 2). Specifically, agreeableness was associated with greater compliance (1) with and without controlling for demographic covariates, (2) with and without controlling for the other Big Five traits, and (3) when assessing both past health behaviors and intended future health behaviors. 
Table 2

Sensitivity Analyses: Personality Predictors of COVID-19 Preventive Health Behaviors

\begin{tabular}{|c|c|c|c|c|c|c|c|}
\hline $\begin{array}{l}\text { Sample A } \\
\text { (Longitudinal) }\end{array}$ & B & $95 \%$ CI & $p$ & $\begin{array}{l}\text { Sample B } \\
\text { (Cross-Sectional) }\end{array}$ & B & $95 \%$ CI & $p$ \\
\hline Agreeableness & 0.27 & $0.20,0.34$ & $<.001$ & Agreeableness & 0.14 & $0.04,0.23$ & .006 \\
\hline Openness & 0.12 & $0.05,0.19$ & .001 & Openness & 0.22 & $0.12,0.31$ & $<.001$ \\
\hline Conscientiousness & 0.16 & $0.09,0.22$ & $<.001$ & Conscientiousness & 0.07 & $-0.02,0.17$ & .141 \\
\hline Extraversion & 0.14 & $0.07,0.21$ & $<.001$ & Extraversion & 0.10 & $-0.00,0.19$ & .055 \\
\hline Neuroticism & -0.05 & $-0.12,0.02$ & .172 & Neuroticism & 0.01 & $-0.08,0.11$ & .771 \\
\hline
\end{tabular}

B. Sensitivity Analysis 2: Unique Effects Controlling for Other Big Five Traits

\begin{tabular}{|c|c|c|c|c|c|c|c|}
\hline $\begin{array}{l}\text { Sample A } \\
\text { (Longitudinal) }\end{array}$ & B & $95 \%$ CI & $p$ & $\begin{array}{l}\text { Sample B } \\
\text { (Cross-Sectional) }\end{array}$ & B & $95 \% \mathrm{CI}$ & $p$ \\
\hline Agreeableness & 0.25 & $0.17,0.32$ & $<.001$ & Agreeableness & 0.10 & $0.00,0.20$ & .041 \\
\hline Openness & 0.03 & $-0.04,0.10$ & .333 & Openness & 0.19 & $0.09,0.29$ & $<.001$ \\
\hline Conscientiousness & 0.09 & $0.01,0.17$ & .027 & Conscientiousness & 0.07 & $-0.05,0.18$ & .251 \\
\hline Extraversion & 0.11 & $0.04,0.18$ & .004 & Extraversion & 0.06 & $-0.05,0.16$ & .312 \\
\hline Neuroticism & 0.11 & $0.03,0.19$ & .006 & Neuroticism & 0.12 & $0.00,0.23$ & .041 \\
\hline \multicolumn{8}{|c|}{ C. Sensitivity Analysis 3: Effects on Intended Future Behaviors } \\
\hline $\begin{array}{l}\text { Sample A } \\
\text { (Longitudinal) }\end{array}$ & B & $95 \% \mathrm{CI}$ & $p$ & $\begin{array}{l}\text { Sample B } \\
\text { (Cross-Sectional) }\end{array}$ & B & $95 \% \mathrm{CI}$ & $p$ \\
\hline Agreeableness & 0.25 & $0.18,0.32$ & $<.001$ & Agreeableness & 0.12 & $0.02,0.22$ & .015 \\
\hline Openness & 0.09 & $0.02,0.16$ & .009 & Openness & 0.14 & $0.05,0.24$ & .003 \\
\hline Conscientiousness & 0.11 & $0.04,0.18$ & .002 & Conscientiousness & 0.12 & $0.02,0.21$ & .014 \\
\hline Extraversion & 0.09 & $0.03,0.16$ & .007 & Extraversion & 0.12 & $0.02,0.21$ & .016 \\
\hline Neuroticism & -0.04 & $-0.12,0.03$ & .217 & Neuroticism & -0.03 & $-0.13,0.07$ & .569 \\
\hline
\end{tabular}

Note. Each row in panels $\mathrm{A}$ and $\mathrm{C}$ show results from a separate model. Age, education, gender, racial and ethnic identity, and political affiliation were included as covariates in the models shown in Panel C. 


\section{Discussion}

The present research bridges theory from personality and health psychology to test the generalizability of long-standing theory in the context of a real-world health crisis and, in turn, provide actionable information to an urgent public health crisis. We found that personality was a powerful predictor of compliance with CDC-recommended health behaviors aimed at slowing the spread of COVID-19. Consistent with the health behavior model of personality, these findings highlight the role of personality in predicting health behaviors (3, 7). Most prior work on personality and health behaviors has focused on self-protecting behaviors that are largely selfdirected (e.g., exercise) or doctor-mandated (e.g., medication adherence) (4). The present work is unique in that we examined behaviors that are both self- and community-protecting and that are mandated at the societal level. Even in this context, in which one might expect strong social mandates to overpower individual differences, personality remained a strong predictor of compliance. However, the relative predictive utility of Big Five traits compared to one another differed somewhat from prior research, underscoring the importance of incorporating both the person and the situation into the health behavior model of personality. Specifically, agreeableness, rather than conscientiousness, was the most consistent predictor of COVID-19 preventive health behaviors. Highly agreeable people's compassion for others may drive them to slow disease spread while their tendency toward cooperation may make them more compliant with societal mandates.

In the present research, the effect of agreeableness on health behaviors was consistent across five months and across diverse individuals, suggesting it may represent a highly-scalable target for optimizing health-behavior messaging on a large-scale as the pandemic continues to unfold. Current health-behavior messaging, which has focused on appeals to agreeableness by 
emphasizing the community-protective benefits of slowing the spread of COVID-19, is likely effectively reaching agreeable individuals and should be maintained. However, these appeals to agreeableness may not be effective for less agreeable individuals who are most likely to ignore behavioral mandates. A two-fold approach may be useful for addressing this problem. First, interventions to increase compassion in less agreeable individuals may improve the effectiveness of current messaging (18). However, interventions that aim to change personality may not be effective or feasible on a large-scale, suggesting that adapting health-behavior messaging to better reach less agreeable individuals may be a more viable approach. Namely, adding alternative messaging that does not rely as heavily on compassion-for example, messaging that focuses on self-protection (19) rather than community-protection-may be more effective for less agreeable individuals. Improving health-behavior messaging to reach less agreeable individuals has the potential to improve compliance with CDC-recommended health behaviors on a large-scale and in turn, slow the spread of COVID-19 and save lives.

\section{Concluding Remark}

The present research highlights the importance of testing long-standing psychological theories using rigorous methods in the context of real-world crises. By doing so, we gain valuable insights that simultaneously improve theory and inform policy. 


\section{References}

1. Cheng VC, Wong S, Chuang VW, So SY, Chen JH. The role of community-wide wearing of face mask for control of coronavirus disease 2019 (covid-19) epidemic due to SARS-CoV-2. J of Infection. 2020; 81: 107-114.

2. Mervosh, FM, Fernandez M, Robertson C. Mask rules expand across U.S. as clashes over the mandates intensify. New York Times. 2020.

3. Kern ML, Friedman HS. Personality and pathways of influence on physical health. Soc. and Pers Psychol Compass. 201; 5: 76-87.

4. Turiano NA, Hill P, Graham EK, \& Mroczek DK. 22 associations between personality and health behaviors across the life span. The Oxford Handbook of Integrative Health Science. 2018; 05.

5. Dutta-Bergman MJ. The linear interaction model of personality effects in health communication. Health Commun. 2003; 15: 101-116.

6. Soto CJ, John OP. Short and extra-short forms of the Big Five Inventory-2: The BFI-2-S and BFI-2-XS. J of Res in Pers. 20177.

7. Smith TW. Personality as risk and resilience in physical health. Current Directions in Psych Sci. 2006; 15, 227-231.

8. Volk S, Thöni C, Ruigrok W. Personality, personal values and cooperation preferences in public goods games: A longitudinal study. Personality and Individ Differences. 2011: 50: $810-815$.

9. Harper CA, Satchell LP, Fido D, Latzman RD. Functional fear predicts public health compliance in the COVID-19 pandemic. Int. J of Ment Health and Addict. 2020. 
10. Friedman HS. Long-Term relations of personality and health: Dynamisms, mechanisms, tropisms. J of Pers. 2000; 68: 1-19.

11. Graham EK, Weston SJ, Turiano NA, et al. Is healthy neuroticism associated with health behaviors? A coordinated integrative data analysis. Collabra: Psychol. 2020; 6.

12. U.S. Center for Disease Control, “Covid-19: Preventing getting sick.” (Updated 2020, July 30).

13. Zajenkowski M, Jonason PK, Leniarska M, Kozakiewicz Z. Who complies with the restrictions to reduce the spread of COVID-19?: Personality and perceptions of the COVID-19 situation. Pers and Ind Differences. 2020; 110199.

14. Aschwanden D, Strickhouser JE, Sesker AA, Lee JH, Luchetti M. Psychological and behavioural responses to coronavirus disease 2019: The role of personality. Eur J of Pers. 2020.

15. Blagov PS. Adaptive and dark personality traits in the Covid-19 pandemic: Predicting health-behavior endorsement and the appeal of public-health messages. Soc Psychol and Pers Sci. 2020.

16. Champely S. pwr: Basic Functions for Power Analysis. R package version 1.2-2. 2018. https://CRAN.R-project.org/package=pwr.

17. Pinheiro J, Bates D, DebRoy S, Sarkar D, \& R Core Team. nlme: linear and nonlinear mixed effects models. R package version 3.1-149. 2020. https://CRAN.Rproject.org/package $=$ nlme.

18. Zaki J. Catastrophe compassion: Understanding and extending prosociality under crisis. Trends in Cogn Sci. 2020. 
19. Gandhi M, Beyrer C, Goosby E. Masks Do More Than Protect Others During COVID-

19: Reducing the Inoculum of SARS-CoV-2 to Protect the Wearer, J. of Gen. Intern. Med. 2020. 